\title{
Correction to: Pharmacokinetics and safety of erlotinib and its metabolite OSI-420 in infants and children with primary brain tumors
}

\author{
Samuel J. Reddick ${ }^{1}$. Olivia Campagne ${ }^{1} \cdot$ Jie Huang $^{2} \cdot$ Arzu Onar-Thomas $^{2} \cdot$ Alberto Broniscer $^{3} \cdot$ Amar Gajjar $^{3}$. \\ Clinton F. Stewart ${ }^{1}$
}

Published online: 7 January 2020

(c) Springer-Verlag GmbH Germany, part of Springer Nature 2020

\section{Correction to: \\ Cancer Chemotherapy and Pharmacology \\ (2019) 84:829-838 \\ https://doi.org/10.1007/s00280-019-03921-3}

In the original publication of the article, the authors wish to note the following error:

Reddick et al. "Pharmacokinetics and Safety of Erlotinib and its Metabolite OSI-420 in Infants and Children with Primary Brain Tumors." Cancer Chemother Pharmacol. 2019 Oct;84(4):829-838. https://doi.org/10.1007/s0028
0-019-03921-3. Epub 2019 Aug 7. PMID: 31392390 was not supported by NIH grant R25CA23944.

The original article can be found online at https://doi.org/10.1007/ s00280-019-03921-3.

Clinton F. Stewart

clinton.stewart@stjude.org

1 Department of Pharmaceutical Sciences, St. Jude Children's Research Hospital, 262 Danny Thomas Place, Memphis, TN 38105-2794, USA

2 Department of Biostatistics, St. Jude Children's Research Hospital, Memphis, TN, USA

3 Division of Neuro-Oncology, Department of Oncology, St. Jude Children's Research Hospital, Memphis, TN, USA 